\title{
Indigenous knowledge on preservative plants and preservation techniques of milk and milk products in south wollo zone, northern ethiopia
}

\begin{abstract}
Background: Indigenous knowledge on traditional milk handling practice and traditional plants is of tremendous aimportance in many societies, including most rural African communities. The indigenous knowledge is especially important to preserve milk and its products and as traditional medicines. In this study, the traditional milk and milk products handling practices was known and the milk preservative plants used in the study area were identified.

Methods: The study was conducted around Dessie administrative city. A total of one hundred twenty women, twenty from each of the six PAs were individually interviewed using semi-structured questionnaire. Moreover, samples of the preservative plants were taken from the field to identify their scientific name. The data collected was analyzed by using SPSS software and explained by descriptive statistics.

Results: Only few respondents $(10 \%)$ practice adequate sanitary practices before and after milking. About $57 \%$ of the respondents used locally growing milk preservative plants for washing and fumigating their milk equipment used for milking, storing and processing with the intention of extending the fermentation time and provide good flavor for the milk. The major preservative plants to clean the milk vessels were Lippia adoensis, Senecio myriocephalus, Sida cuneifolia, Lhymus schimperi, Hypericum revolutum and Rumex nervosus while the most frequently used plants to smoke milk utensils were Olea Africana, Clerodendrum myricoides, Terminalia brownie, Juniperous procera and 'Mitie'.

Conclusion: Majority of the households of the study area did not carry out adequate milk sanitary practices hence the milk sanitary practices of the area should be improved. The preservative plants identified in this study were imperative to the community. The active ingredients of these plants, i.e., the extent and technique of utilization, their efficacy on the microorganisms and impact on the consumer body should be further studied.
\end{abstract}

Volume 3 Issue 2 - 2018

\author{
Tewodros Alemu, Muluken Girma \\ Department of Animal Science, Wollo University, Ethiopia
}

Correspondence: Tewodros Alemu, Wollo University, College of Agriculture, Department of Animal Science, Dessie Campus, Ethiopia,Tel+25191015 258I, Email teda2010@gmail.com

Received: February 14, 2018| Published: March 27, 2018

Keywords: milk, milk product, technique, preservative plant

Abbreviations: ANRS, afar national regional state; OAZ, oromia administrative Zone; Pas, peasant associations; SPSS, statical packages for social sciences; SWZ, south wollo zone; WU, wollo University

\section{Background}

Storage stability problems of dairy products exacerbated by high ambient temperatures and distances that producers have to travel to bring the products to market places make it necessary for smallholders to seek products with a better shelf-life or to modify the processing methods of existing once to get products of better shelf-life. The first step that the producers or product handlers can take to ensure a high quality product is to make sure that the production and the manufacturing process are hygienic. These will result in fewer spoilage organisms in the dairy products and thus better quality with longer shelf life in the final products. Another option to ensure good quality is to take maximum care in handling and storage of the products during transport and marketing. The fact that milk is relatively perishable and a high percentage of it is consumed in a relatively natural state, handling of milk and its products to preserve its natural and desired characteristics is very important. ${ }^{1}$ The less perishable the products, the longer the smallholders can retain it to obtain good price and surplus made during the production season can be stored for consumption during the season in which the products are in short supply. Smallholders add different spices to butter as a preservative and /or to enhance its flavor for cooking. ${ }^{2}$ In areas where the climate is hot, the raw milk spoils easily during storage unless it is cooled or when possible treated with preservatives. But these preservatives are not readily available in rural areas and cooling systems are not feasible because of lack of facilities. ${ }^{3}$ In these areas, the farmers have to rely on traditional technology to increase the storage stability of milk and milk products either by converting the milk to its stable products like butter or by treating with traditional preservatives.

Identification and characterization of the traditional herbs and methods of utilization could be very crucial in developing appropriate technologies for milk handling and preservation. The study was also important for giving chance for further study of the materials. This study was therefore designed with the objectives to identify and characterize the traditional preservative materials of milk and milk products; and to assess the indigenous knowledge on the preservation techniques in and around Dessie. 


\section{Materials and methods \\ Description of the study area}

The study was conducted around Dessie administrative city which is a potential milk shed area. Dessie administrative city is the capital city of SWZ and it is located at $401 \mathrm{~km}$ north of Addis Ababa (capital city of Ethiopia). The area comprises 16 PAs (the smallest administrative unit), from which six of them were rural PAs and the rest ten were city PAs. The study was particularly conducted in the six rural PAs (Tita, Qurqur, Boru-meda, Boru-selasie, Gerado-15 and Gerado-16).The predominant agricultural production system in this area is mixed crop-livestock farming.

\section{Sampling technique and sample size}

Six of the peasant associations located around Dessie was selected. From each PAs, twenty women who owned milking cows and process milk was purposively picked up and interviewed. Accordingly, a total of one hundred twenty participants from the study area were individually interviewed using a semi-structured questionnaire in the study to be undertaken.

\section{Data sources and method of data collection}

Primary and secondary data was used for the analysis. Semistructured questionnaire was prepared to collect information. The questionnaire was pre-tested before the actual survey. Enumerators was recruited and trained to manage the formal survey, using the semi-structured questionnaire with female farmers. The preservative plant species identified from the questionnaire was further transported to the herbarium of Addis Ababa to identify their scientific names. Relevant secondary data was collected from internet and annual reports.

\section{Data analysis}

The data collected was analyzed qualitatively and quantitatively. Generally for the qualitative and quantitative data generated through the survey descriptive statistics like mean and percentages was used to examine and explain the milk handling practices and preservation techniques in the area. SPSS computer software package version 20 was $^{4}$ used to analyze the collected data. The mean and percentage values of various parameters were compared across the studied PAs.

\section{Results and discussion}

\section{Milk and milk products handling practices}

Only few respondents $(10 \%)$ practice adequate sanitary practices before and after milking. This result agrees with ${ }^{5}$ who indicated only few respondents $(10.3 \%)$ were washing udder of their cow after milking. Whereas $55 \%$ of the respondents practice udder washing before milking. The result of this study is in contrast to, ${ }^{6}$ who reported that most farmers do not wash the udder of their cows before milking; they assume allowing the calf to suckle before milking is sufficient to clean the teats. The current study also disagreed with the report of ${ }^{7}$ who indicated that udder of the cow is washed before milking only by few farmers $(5.6 \%)$. In all of the respondents, calves were allowed to suckle their dams prior to milking for some time. Only $2 \%$ of the respondents use individual towel to dry the udder of their cows (Table $1)$.
In most instances, women dip their fingers into the milk bucket and moisten the teats of the cow to facilitate milking. This practice may allow microbial contamination of the milk from the milker's hand. The lack of proper cleaning of udder could lower milk quality and have significant concern on public health. ${ }^{8}$ About $57 \%$ of the respondents used locally growing milk preservative plants for washing and fumigating their milk equipment used for milking, storing and processing with the intention of extending the fermentation time and provide good flavor for the milk (Table 1). The equipment were washed thoroughly using different plants prior to smoking. The plants used for the cleaning of milking and fermenting utensils are presented in Table 2. However cleaning plants differ from place to place and even from household to household based up on preferences.?

Table I Milking and hygienic practices in the study area

\begin{tabular}{ll}
\hline Milking practices & Reponses (\%) \\
\hline Udder washing before milking & 55 \\
Udder washing after milking & 10 \\
Suckling and milking & 100 \\
Use of individual towel to dry the udder of cow & 2 \\
$\begin{array}{l}\text { Use of local plants for washing and fumigating milk } \\
\text { equipment }\end{array}$ & 57 \\
\hline
\end{tabular}

\section{Locally growing plants used for cleaning milk utensils}

The most frequently used cleaning plants for milk equipment in the study area were Lippia adoensis, Senecio myriocephalus, Sida cuneifolia, Lhymus schimperi, Hypericum revolutum and Rumex nervosus (Table 2) (Figure 1). About $83 \%$ of the nature of these plants was shrubs whereas $17 \%$ was herb. According to the respondents, the techniques of application of these preservative plants were rubbing the leaf and/or twig of the plants against the internal wall of the milk vessels. The result is similar with the observations made by Coppock et al. ${ }^{9}$ in the semi-arid pastoral system of Ethiopia, who reported a milk utensil locally called Gorfa may be scrubbed with leaves of locally growing preservative plants before being filled with milk. Plants used for rubbing milking vessels deserve further investigation to determine their active ingredient and the efficacy of the active ingredients on the desirable and /or undesirable microorganisms.

As a result of their readily availability in the surrounding of the area, $100 \%$ of the respondents use Lippia adoensis and Rumex nervosus as cleaning plants (Table 2). The availability and the degree of utilization of the cleaning plants differ from place to place and even from household to household based upon preferences and abundance indicating the variety of materials that need to be exhaustively studied. All of the respondents claimed that cleaning plants of their choice were being used as they were known to improve the flavor of their milk. Moreover, when fermentation rate increase, the milk storage vessels were washed with the plants to retard the fermentation rate. The plants might act by helping to inoculate some desirable organisms in the milk or selectively inhibit the growth of undesirable acid forming organisms and create ideal environment for the former groups to grow and take the advantage for proliferation. Nowadays some of the participants who are near to and have road access did not ferment their milk for butter making. Around $43 \%$ of the respondents 
in the study area directly sold their milk for the nearby collectors coming to their home gate immediately after milking. Hence, these households did not use preservative plants instead detergents (Ajax, Ommo, etc.) and thin wire was used for washing their milk containers.

Table 2 Locally growing plants used for cleaning/washing milk utensils

\begin{tabular}{|c|c|c|c|c|c|c|c|c|c|c|}
\hline \multicolumn{2}{|c|}{ Name of the plants } & \multirow{2}{*}{$\begin{array}{l}\text { Growth } \\
\text { form }\end{array}$} & \multirow{2}{*}{ Parts used } & \multirow{2}{*}{$\begin{array}{l}\text { Application } \\
\text { technique }\end{array}$} & \multicolumn{6}{|c|}{ Status of utilization } \\
\hline Local & Scientific & & & & 011 & 012 & 013 & 014 & 015 & 016 \\
\hline Kessie & Lippia adoensis & Shrub & Leaf & Rubbing & $\sqrt{ }$ & $\sqrt{ }$ & $\sqrt{ }$ & $\sqrt{ }$ & $\sqrt{ }$ & $\sqrt{ }$ \\
\hline Weynagift & $\begin{array}{l}\text { Senecio } \\
\text { myriocephalus }\end{array}$ & Shrub & Leaf & Rubbing & $\sqrt{ }$ & $x$ & $\sqrt{ }$ & $\sqrt{ }$ & $x$ & $x$ \\
\hline Chifirig & Sida cuneifolia & Shrub & Leaf and twig & Rubbing & $\sqrt{ }$ & $\sqrt{ }$ & $\sqrt{ }$ & $\sqrt{ }$ & $\mathrm{X}$ & $\sqrt{ }$ \\
\hline Tosign & Lhymus schimperi & Herb & Leaf & Rubbing & $x$ & $\sqrt{ }$ & $\sqrt{ }$ & $\sqrt{ }$ & $\sqrt{ }$ & $\sqrt{ }$ \\
\hline Amija & $\begin{array}{l}\text { Hypericum } \\
\text { revolutum }\end{array}$ & Shrub & Leaf & Rubbing & $x$ & $\sqrt{ }$ & $\sqrt{ }$ & $x$ & $x$ & $x$ \\
\hline Embacho & Rumex nervosus & Shrub & Leaf & Rubbing & $\sqrt{ }$ & $\sqrt{ }$ & $\sqrt{ }$ & $\sqrt{ }$ & $\sqrt{ }$ & $\sqrt{ }$ \\
\hline
\end{tabular}

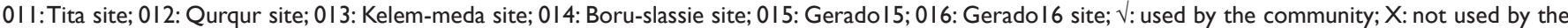
community
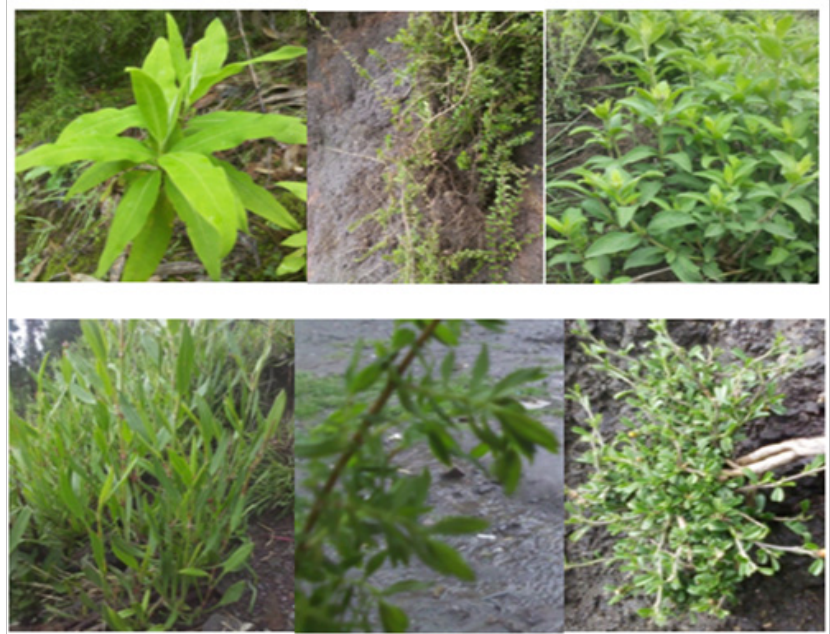

Figure I Locally growing washing plants used as milk preservative in the study area.

\section{Locally growing plants used for smoking milk utensils}

The most frequently used plant for smoking milk vessels in the study area were Olea Africana, 'mitie', Clerodendrum myricoides, Terminalia brownie and Juniperous procera (Table 3), (Figure 2), (Figure 3). Majority of the nature of these plants $(80 \%)$ were trees whereas $20 \%$ was shrubs. According to the respondents, the techniques of application of these preservative plants to the milk utensils were either only by burning or both burning and immersing of the plant inside the milk vessels to include the plants smoke into the container. Majority of the plant materials $(60 \%)$ were both burned and immersed to incorporate their smoke to the inside part of the milk equipment. The stem part of the plant was used from all the smoking plants $(100 \%)$ for preserving the milk nevertheless in case of Clerodendrum myricoides the stem was used by the respondents when the plant was matured enough. Root was also used from Olea Africana, 'Mitie' and Clerodendrum myricoides. In case of Terminalia brownie the bark may be used together with the stem.

Table 3 Locally growing plants used for smoking milk vessels

\begin{tabular}{|c|c|c|c|c|c|c|c|c|c|c|}
\hline \multicolumn{2}{|c|}{ Name of the plants } & \multirow{2}{*}{$\begin{array}{l}\text { Growth } \\
\text { form }\end{array}$} & \multirow{2}{*}{ Parts used } & \multirow{2}{*}{$\begin{array}{l}\text { Application } \\
\text { technique }\end{array}$} & \multicolumn{6}{|c|}{ Status of utilization } \\
\hline Local & Scientific & & & & 011 & 012 & 013 & 014 & 015 & 016 \\
\hline Weyra & Olea Africana & Tree & Root and stem & $\begin{array}{l}\text { Burning and/or } \\
\text { immersing }\end{array}$ & $\sqrt{ }$ & $\sqrt{ }$ & $\sqrt{ }$ & $\sqrt{ }$ & $\sqrt{ }$ & $\sqrt{ }$ \\
\hline Misirij & Clerodendrum myricoides & Shrub & Root and stem & Burning & $\sqrt{ }$ & $\sqrt{ }$ & $\sqrt{ }$ & $\sqrt{ }$ & $\sqrt{ }$ & $\sqrt{ }$ \\
\hline Mitie & Unknown & Tree & Root and stem & $\begin{array}{l}\text { Burning and/or } \\
\text { immersing }\end{array}$ & $\sqrt{ }$ & $\sqrt{ }$ & $\sqrt{ }$ & $\sqrt{ }$ & $\sqrt{ }$ & $\sqrt{ }$ \\
\hline Abalo & Terminalia brownii & Tree & Stem and bark & $\begin{array}{l}\text { Burning and/or } \\
\text { immersing }\end{array}$ & $x$ & $\sqrt{ }$ & $x$ & $\sqrt{ }$ & $\sqrt{ }$ & $\sqrt{ }$ \\
\hline Tid & Juniperous procera & Tree & Stem & Burning & $\sqrt{ }$ & $\sqrt{ }$ & $\sqrt{ }$ & $\sqrt{ }$ & $\sqrt{ }$ & $\sqrt{ }$ \\
\hline
\end{tabular}

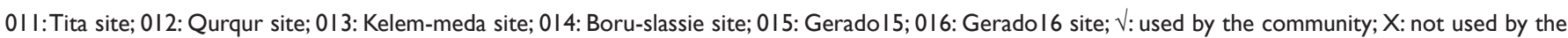
community 


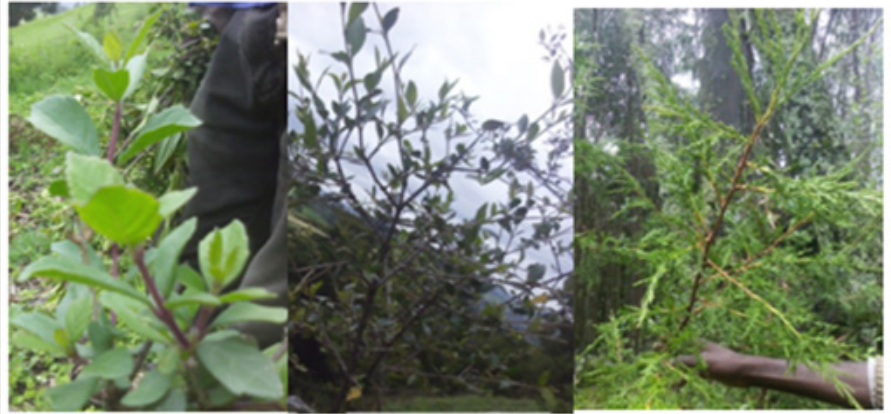

Figure 2 Locally growing smoking plants used as milk preservative in the study area.

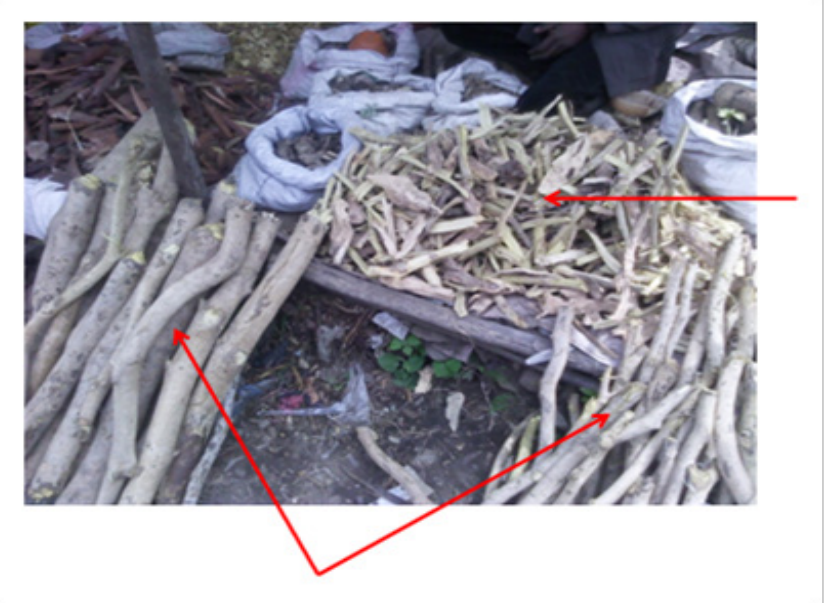

Figure 3 Smoking plants purchased from markets used as milk preservative in the study area.

Smoking plants were used to convey good flavor to the milk and milk products. This result agreed with the result of Sintayehu et al. ${ }^{10}$ who reported that milking utensils were smoked with different aroma producing plants like Olea africana and Juniperous procera. This result also agrees with the report of $\mathrm{FAO}^{11}$ who stated that the milking equipment in Borana was smoked by burning chips of Olea africana. Similarly ${ }^{12}$ from North western Ethiopian highlands stated majority of the farmers used smoking plants like Olean Africana, and Juniperous procera. The result is different from the findings of Coppock et al. ${ }^{9}$ who indicated households in semiarid pastoral system of Ethiopia smoke their milk processing vessels with burning chips of Acacia nilotica, Cordia glarfa, Cordia ovalis or Combertum molle. Except Olea africana the current study result is also different from Alganesh Tola $^{13}$ who reported in Eastern Wollega Deinbollo kilimandshorica, Syzygium guinecnse, Heeria reticulala and Olea africana were the most commonly used smoking plants.

Similar to the cleaning plants, the use of smoking plants differs from place to place and even from household to household. For example, Terminalia brownii was not used by respondents from Tita and Borumeda sampling sites (Table 3). Stem of Clerodendrum myricoides was used as preservative if it was matured enough. According to the respondents, smoking of milking and storage vessels was frequently done in order to extend the fermentation time besides its provision of good flavor. This agrees with the finding of Mogessie Ashenafi et al. ${ }^{14}$ that smoking reduced the undesirable microbial contamination that enhances the rate of fermentation. Whenever there is high production of milk, the milking and storage vessels were not smoked to increase the rate of fermentation. $\mathrm{In}^{9}$ semi-arid pastoral system of Ethiopia also reported that sterilization helps to obtain an appropriate rate of fermentation. In cases where containers were limited and /or people need to sour fresh milk daily, the milk container may be reused without scrubbing or fumigating. During the cold season some households put the milk close to fireplace in order to facilitate fermentation within the shortest time possible if they have surplus milk and want to churn every day. The milk containers were fumigated by inverting them over the smoking plant chips until the smoke died out. The residual charcoal pieces were brushed out followed by rinsing with water. However, some respondents (43\%) who did not ferment their milk sell fresh milk to the milk collectors to be sold at the nearby town (Dessie). From the smoking plants, Terminalia brownii and 'Mitie' were not naturally grown in the surrounding of the sampling sites of the study area. These plants were grown far away from sample sites in the lowlands of the study area near to the gorge of Abay River and neighboring Region and Zone (ANRS and OAZ). The communities of the study area obtained these smoking plant materials by purchasing from the nearby local markets (Figure 3).

\section{Conclusion}

Majority of the households of the study area did not carry out adequate milk sanitary practices hence the milk sanitary practices of the study area should be improved. The major preservative plants to clean the milk vessels were Lippia adoensis, Senecio myriocephalus, Sida cuneifolia, Lhymus schimperi, Hypericum revolutum and Rumex nervosus while the most frequently used plants to smoke milk utensils were Olea Africana, 'Mitie', Clerodendrum myricoides, Terminalia brownie and Juniperous procera. Milk vessel washing and smoking plants identified in this study deserves further investigation, i.e., the active ingredients of the identified plants should be studied in detail. Particularly, their effectiveness to keep the product for longer periods without deterioration, the efficacy of the active ingredients on the desirable and/or undesirable microorganisms, the amount and technique of utilization and their impact on the consumer body should be studied.

\section{Acknowledgements}

A sincere thanks is extended to all the development agent of the sampling sites (PAs) who participated in this research work.

\section{Ethics approval and consent to participate}

Not applicable.

\section{Consent for publication}

Not applicable.

\section{Availability of supporting data}

The datasets and plant materials used for analysis of this work are available from the corresponding author on reasonable request.

\section{Competing interests}

The authors declare that they have no competing interests that would otherwise interfere with the results pertaining to this research. 


\section{Funding}

We want to appreciate and thank WU (Ethiopia) for sponsoring this research work.

\section{Authors' contributions}

The corresponding author (author Tewodros A) conceived the research idea. The study was then carried out by author Tewodros A in collaboration with author Muluken G Author Tewodros A together with author Muluken $G$ undertook the collection of experimental samples, performed the analyses, and interpreted the results. The first draft of the manuscript was written by author Tewodros A and author Muluken $G$ read and made final changes to the final manuscript as a research article.

\section{References}

1. Duane A. Cunningham M. Animal Science and Industry. $4^{\text {th }}$ ed. Prentice Hall, Engle wood Clifts: New Jersey; 1991.

2. ILCA (International Livestock Center for Africa). CA Annual Report and Program Highlights. Addis Ababa: ILCA; 1992.

3. O'Mahony F, Peters J. Options for Smallholder Milk Processing in SubSaharan Africa. Addis Ababa: International Livestock Center for Africa (ILCA), Ethiopia; 1987.

4. SPSS (Statistical Package for Social Science). SPSS User's Guide: Statistics (Version 20). USA: Institute Inc; 2012.

5. Fikrineh N, Estefanos T, Esayas A, et al. Production, handling, processing, utilization and marketing of milk in the Mid Rift Valley of Ethiopia. Livestock Research for Rural Development. 2012;24(9).
6. Mbabazi P. Milk industry in Uganda, $1^{\text {st }}$ Edition, Kampala: Fountain Publishers; 2005.

7. Lemma F. Assessment of butter quality and butter making efficiency of new churns compared to smallholders' butter making techniques in East Shoa Zone of Oromia. Alemaya University MSc thesis: Alemaya; 2004.

8. Jayarao BM, Pillai SR, Sawant AA, et al. Guidelines for monitoring bulk tank milk somatic cell and bacterial counts. J. Dairy Sci. 2004;87(10):3561-3573.

9. Coppock DL, Holden SJ, Mulugeta Asefa. Review of dairy marketing and processing in a semiarid pastoral system in Ethiopia. In: RF Brokke, $\mathrm{S}$ Senait, editors. Proceedings of a symposium held at International Livestock Center for Africa (ILCA); 1992. p. 315-334.

10. Sintayehu Y, Fekadu B, Azage T, et al. Dairy production, processing and marketing systems of Shashemene-Dilla area, South Ethiopia. ILRI; 2008 .

11. FAO (Food and Agriculture Organization of the United Nations). The technology of traditional milk products in developing countries. Food and Agriculture Organization of the United Nations, Rome; 1990.

12. Yitaye A, Wurzinger M, Tegegne A, et al. Handling, processing and marketing of milk in the North western Ethiopian highlands. Livestock Research for Rural Development. 2009;21(7):97.

13. Alganesh Tola. Traditional Milk and Milk Products Handling Practices and Raw Milk Quality in Eastern Wollega. Alemaya: Alemaya University MSc Thesis; 2002.

14. Mogessie A, Fekadu B. Effect of container smoking and cleaning on the micro flora and keeping quality of raw milk from a dairy farm in Awassa, Ethiopia. Tropical Science. 1993;33:368-376. 